\title{
Supporting information \\ The effects of sonication and hydrothermal treatments on the optical and chemical properties of carbon dots
}

I-Hua Tsai, Jyun-Ting Li and Chih-Wei Chang*

Department of Chemistry, National Changhua University of Education, Changhua,

50058, Taiwan

*Corresponding author: cwchang@cc.ncue.edu.tw 


\section{Table of contents}

Figure S1: The TEM images of the C-dots ${ }^{\mathrm{MW}}$ (upper) and the C-dots ${ }_{\text {Sonicated }}^{\mathrm{MW}}$ (lower) S3 Figure S2: The emission spectra of (a) the C-dots ${ }^{\mathrm{MW}}$, and (b) the $\mathrm{C}-\operatorname{dots}_{\mathrm{Sonicated}}^{\mathrm{Mw}}$ excited at different wavelengths. (c) The emission peaks at different excitation wavelengths. The emission spectra were fitted by the log-normal equation.

Figure S3: The emission spectra of the C-dots ${ }^{\mathrm{MW}}$ and C-dots ${ }^{\mathrm{MW}}+100 \mu \mathrm{M} \mathrm{Hg}^{2+}$ ions at (a) $\mathrm{pH}=2.55$ (b) $\mathrm{pH}=3.68$ (c) $\mathrm{pH}=4.65$ (d) $\mathrm{pH}=6.58$. (e) the changes of the integrated fluorescence intensity of the $\mathrm{C}-\operatorname{dots}^{\mathrm{MW}}$ and $\mathrm{C}-\operatorname{dots}^{\mathrm{MW}}+100 \mu \mathrm{M} \mathrm{Hg}^{2+}$ ions at different $\mathrm{pH}$. The $\mathrm{F}_{0}$ and the $\mathrm{F}$ indicates the integrated fluorescence intensity of the $\mathrm{C}-\operatorname{dots}^{\mathrm{MW}}$ and C-dots ${ }^{\mathrm{MW}}+100 \mu \mathrm{M} \mathrm{Hg}^{2+}$ ions, respectively.

Figure S4: The emission spectra of (a) C-dots ${ }^{\mathrm{MW}}$ (b) C-dots $\mathrm{Sonicated}^{\mathrm{MW}}$ and (c) C-dott ${ }_{200^{\circ} \mathrm{C}}^{\mathrm{MW}}$ titrated by $\mathrm{Cu}^{2+}$ ion. (d) the Stern-Vomer plots of the C-dots titrated by $\mathrm{Cu}^{2+}$ ion.

Figure S5: The emission spectra of (a) C-dots ${ }^{\mathrm{MW}}$ (b) C-dots $\mathrm{S}_{\text {sonicated }}^{\mathrm{MW}}$ and (c) C-dots $\mathrm{d}_{200^{\circ} \mathrm{C}}^{\mathrm{MW}}$ titrated by $\mathrm{Fe}^{3+}$ ion. (d) the Stern-Vomer plots of the C-dots titrated by $\mathrm{Fe}^{3+}$ ion. S7

Figure S6: (a) the Stern-Volmer plot and (b) the absorbance changes at $430 \mathrm{~nm}$ of the C-dots $\underset{\text { sonicated }}{\mathrm{MW} \text { aneobic }}$. The $\mathrm{F}_{0}$ and $\mathrm{F}$ indicate the integrated fluorescence intensity (excitation wavelength $=350 \mathrm{~nm}$ ) in the absence and the presence of the $\mathrm{Hg}^{2+}$ ions, respectively.

Figure S7: The fluorescence contour maps of (a) the C-dots $\mathrm{s}_{100^{\circ} \mathrm{C}}^{\mathrm{Mw}}$ and (b) the C-dots $\mathrm{S}_{200^{\circ} \mathrm{c}}^{\mathrm{MW}}$. (c) The shifts of the emission peaks vs. excitation wavelengths

Figure S8: The TEM images of the C-dots ${ }_{100^{\circ} \mathrm{C}}^{\mathrm{Mw}}$ (upper) and the C-dots $\mathrm{s}_{200^{\circ} \mathrm{C}}^{\mathrm{Mw}}$ (lower) $\mathrm{S} 10$

Figure S9: The ${ }^{1} \mathrm{H}$ NMR spectra of (a) the $\mathrm{C}-\operatorname{dots}^{\mathrm{MW}}$ (b) the $\mathrm{C}-\operatorname{dots}_{\mathrm{Sonicated}}^{\mathrm{MW}}$ and (c) $\mathrm{C}-\operatorname{dots}_{200^{\circ} \mathrm{C}}^{\mathrm{MW}}$ in $\mathrm{D}_{2} \mathrm{O}$ solution.

Figure S10: The absorption spectra of (a) the C- $\operatorname{dots}_{100^{\circ} \mathrm{C}}^{\mathrm{Mw}}$ and (b) $\mathrm{C}-\operatorname{dots}_{200^{\circ} \mathrm{C}}^{\mathrm{MW}}$ mixed with AOT $(0.1 \%)+\mathrm{AgNO}_{3}$ and exposed to white light LED. The insets indicate the time-evolution of the absorbance at $430 \mathrm{~nm}$.

Table S1: The relative area of each deconvoluted band of the XPS Spectra 

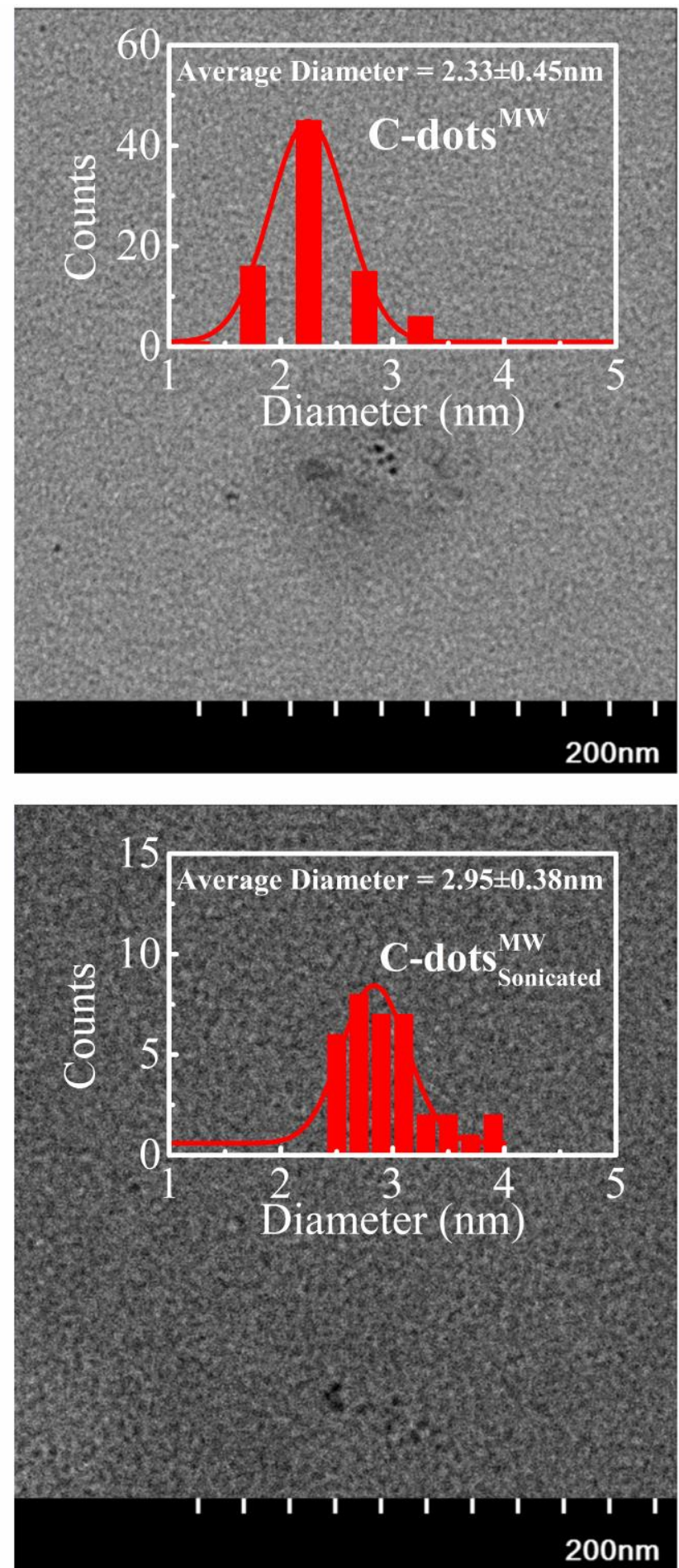

Figure S1: The TEM images of the C-dots ${ }^{\mathrm{MW}}$ (upper) and the $\mathrm{C}-\operatorname{dots}_{\mathrm{Sonicated}}^{\mathrm{MW}}$ (lower) 

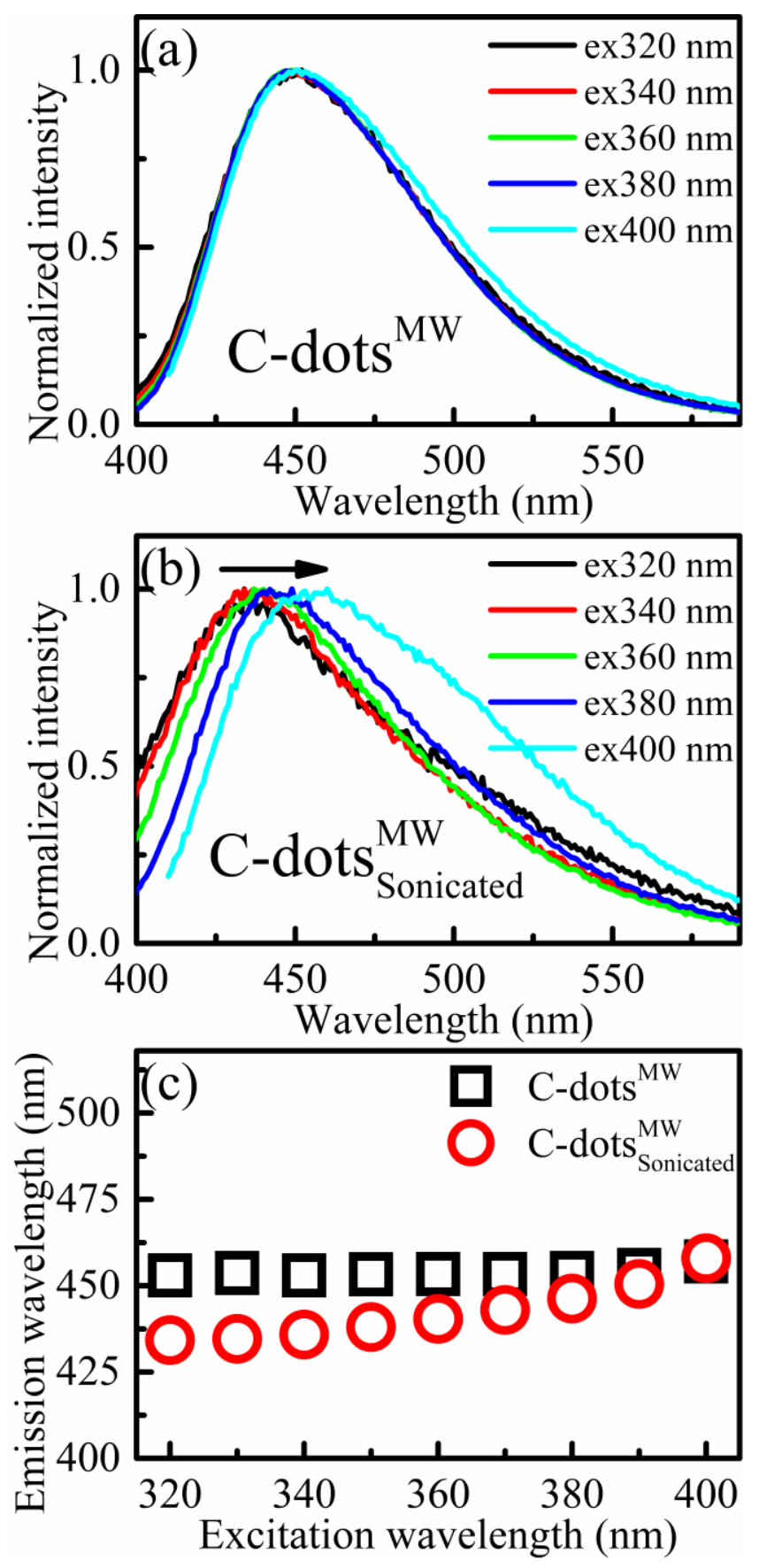

Figure S2: The emission spectra of (a) the C-dots ${ }^{\mathrm{MW}}$, and (b) the C-dots $\mathrm{S}_{\mathrm{Sonicated}}^{\mathrm{MW}}$ excited at different wavelengths. (c) The emission peaks at different excitation wavelengths. The emission spectra were fitted by the log-normal equation. 

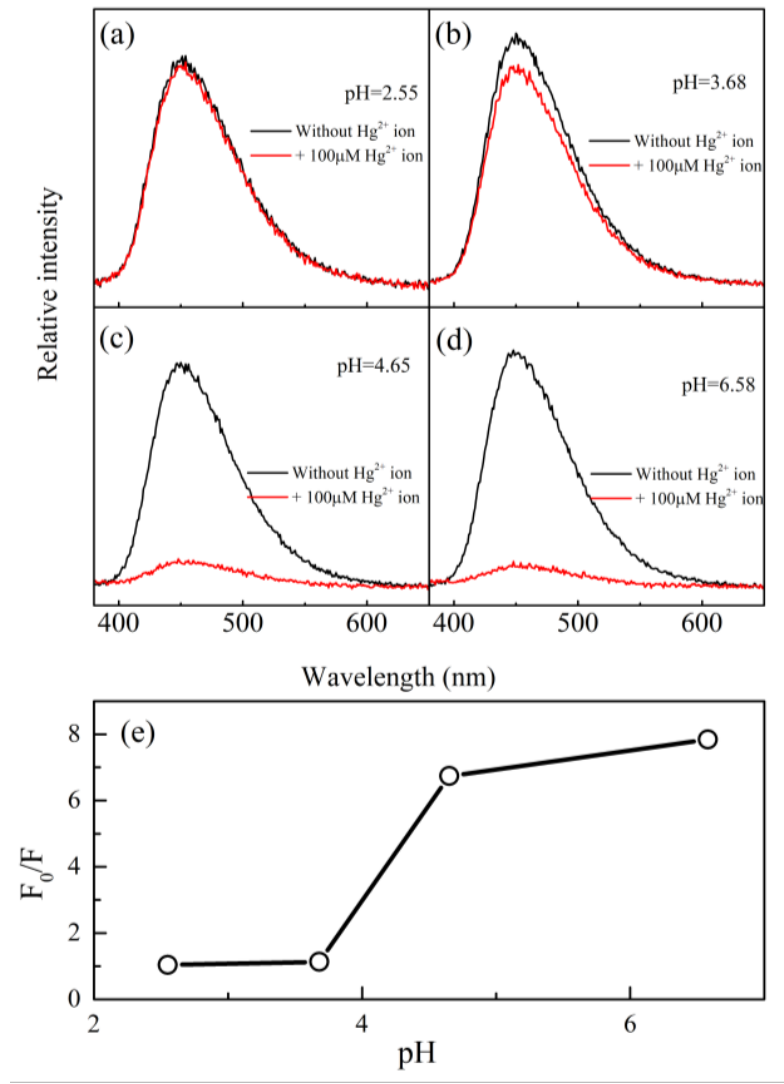

Figure S3: The emission spectra of the C-dots ${ }^{\mathrm{MW}}$ and C-dots ${ }^{\mathrm{MW}}+100 \mu \mathrm{M}$ $\mathrm{Hg}^{2+}$ ions at (a) $\mathrm{pH}=2.55$ (b) $\mathrm{pH}=3.68$ (c) $\mathrm{pH}=4.65$ (d) $\mathrm{pH}=6.58$. (e) the changes of the integrated fluorescence intensity of the $\mathrm{C}$-dots ${ }^{\mathrm{MW}}$ and $\mathrm{C}$ dots $^{\mathrm{MW}}+100 \mu \mathrm{M} \mathrm{Hg}^{2+}$ ions at different $\mathrm{pH}$. The $\mathrm{F}_{0}$ and the $\mathrm{F}$ indicates the integrated fluorescence intensity of the C-dots ${ }^{\mathrm{MW}}$ and C-dots ${ }^{\mathrm{MW}}+100 \mu \mathrm{M}$ $\mathrm{Hg}^{2+}$ ions, respectively. 

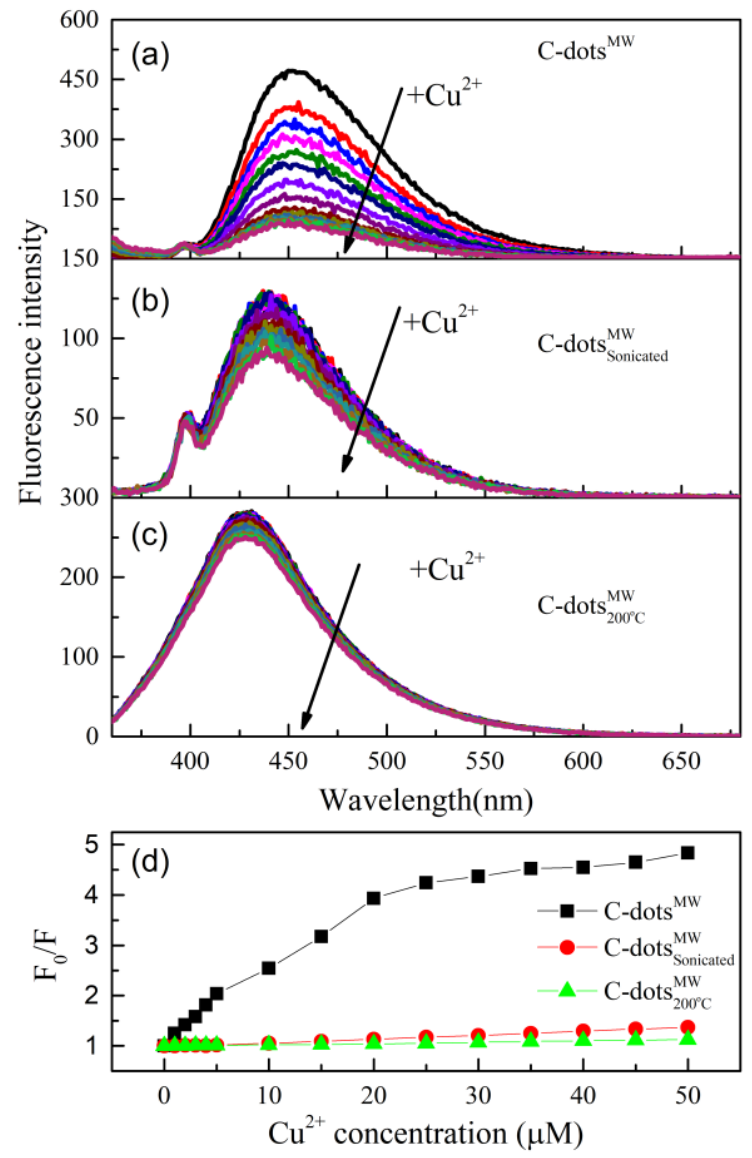

Figure S4: The emission spectra of (a) C-dots ${ }^{\mathrm{MW}}$ (b) C-dots $\mathrm{SWnicated}_{\text {SW }}$ and (c) C-dots ${ }_{200^{\circ} \mathrm{C}}^{\mathrm{Mw}}$ titrated by $\mathrm{Cu}^{2+}$ ion. (d) the Stern-Vomer plots of the C-dots titrated by $\mathrm{Cu}^{2+}$ ion. 

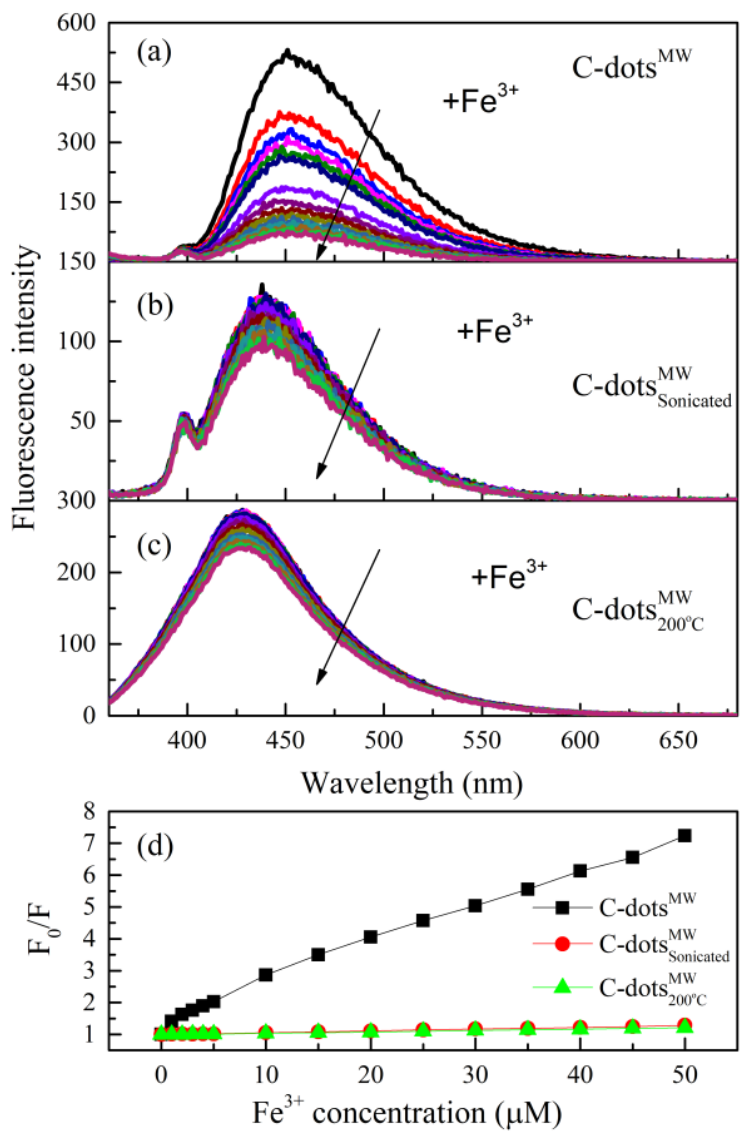

Figure S5: The emission spectra of (a) C-dots ${ }^{\mathrm{MW}}$ (b) $\mathrm{C}-\operatorname{dots}_{\text {Sonicated }}^{\mathrm{MW}}$ and (c) C-dots ${ }_{200^{\circ} \mathrm{C}}^{\mathrm{MW}}$ titrated by $\mathrm{Fe}^{3+}$ ion. (d) the Stern-Vomer plots of the C-dots titrated by $\mathrm{Fe}^{3+}$ ion. 

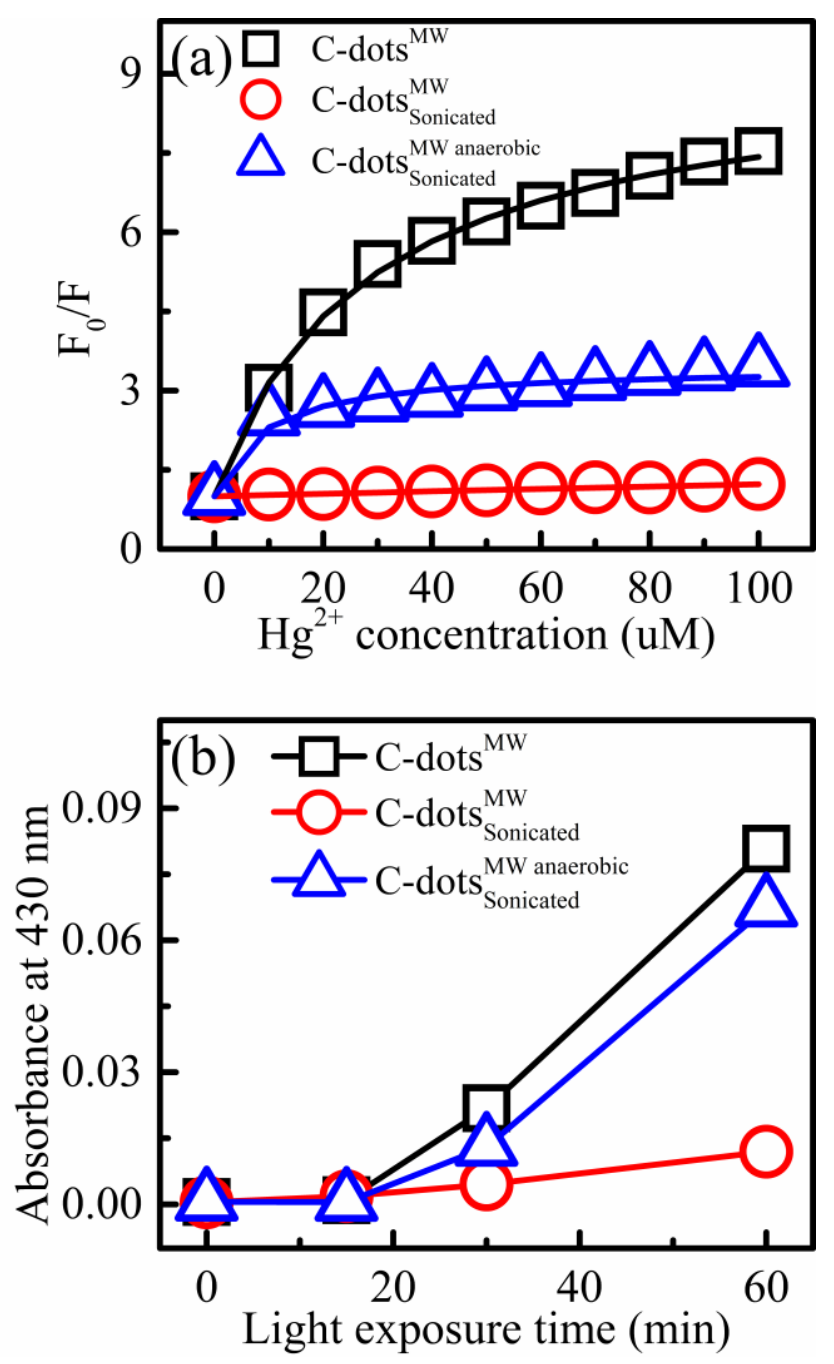

Figure S6: (a) the Stern-Volmer plot and (b) the absorbance changes at 430 $\mathrm{nm}$ of the $\mathrm{C}$-dots $\mathrm{S}_{\text {sonicated }}^{\mathrm{MW} \text { anaeric }}$. The $\mathrm{F}_{0}$ and $\mathrm{F}$ indicate the integrated fluorescence intensity (excitation wavelength $=350 \mathrm{~nm}$ ) in the absence and the presence of the $\mathrm{Hg}^{2+}$ ions, respectively. 

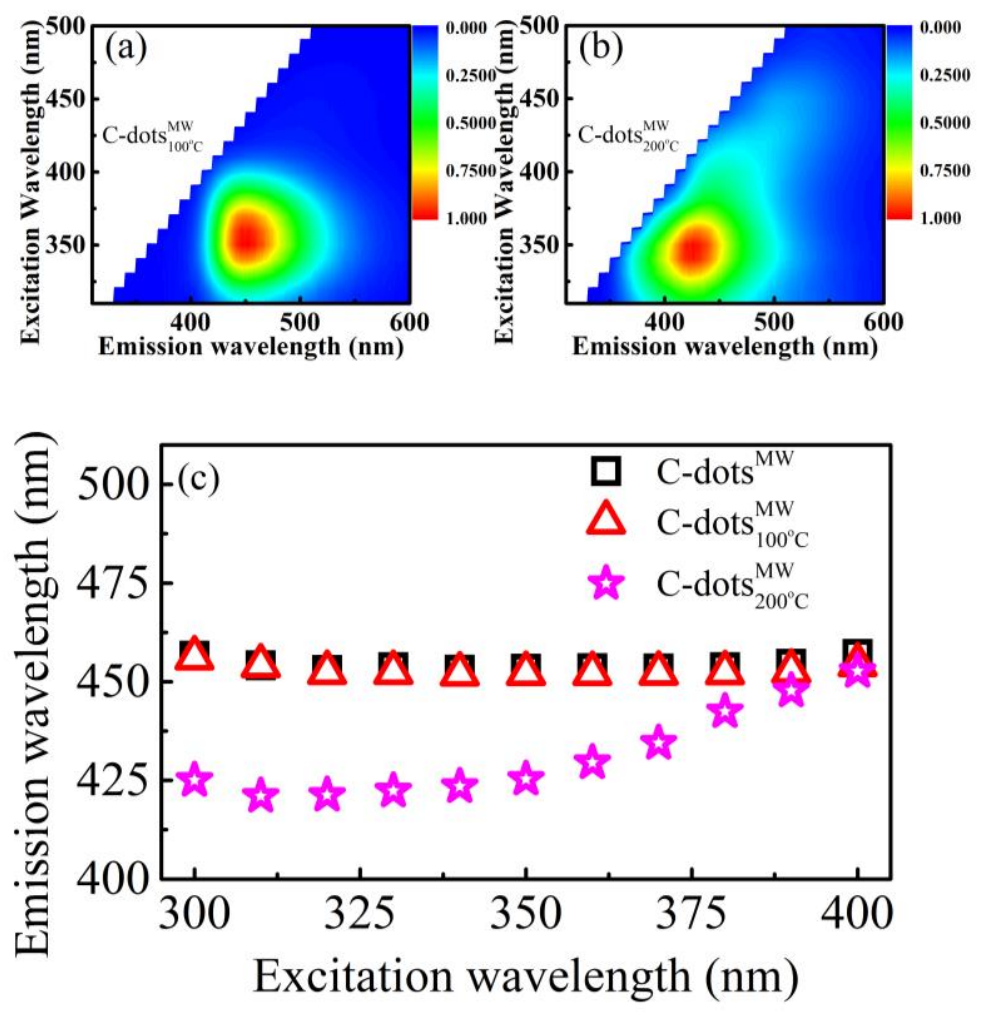

Figure S7: The fluorescence contour maps of (a) the C-dots ${ }_{100^{\circ} \mathrm{C}}^{\mathrm{Mw}}$ and (b) the

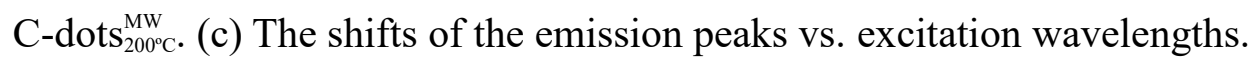



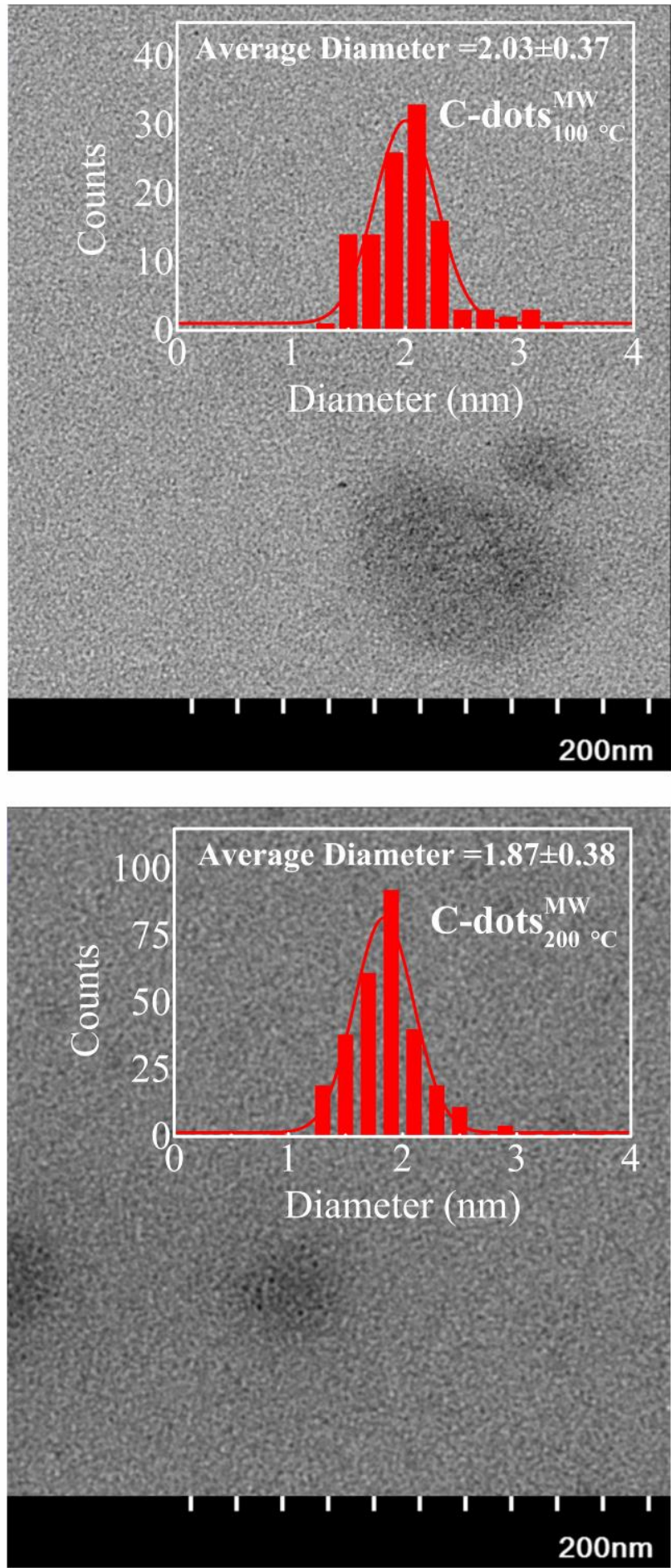

Figure S8: The TEM images of the C-dots ${ }_{100^{\circ} \mathrm{C}}^{\mathrm{Mw}}$ (upper) and the C-dots ${ }_{200^{\circ} \mathrm{C}}^{\mathrm{MW}}$ (lower) 


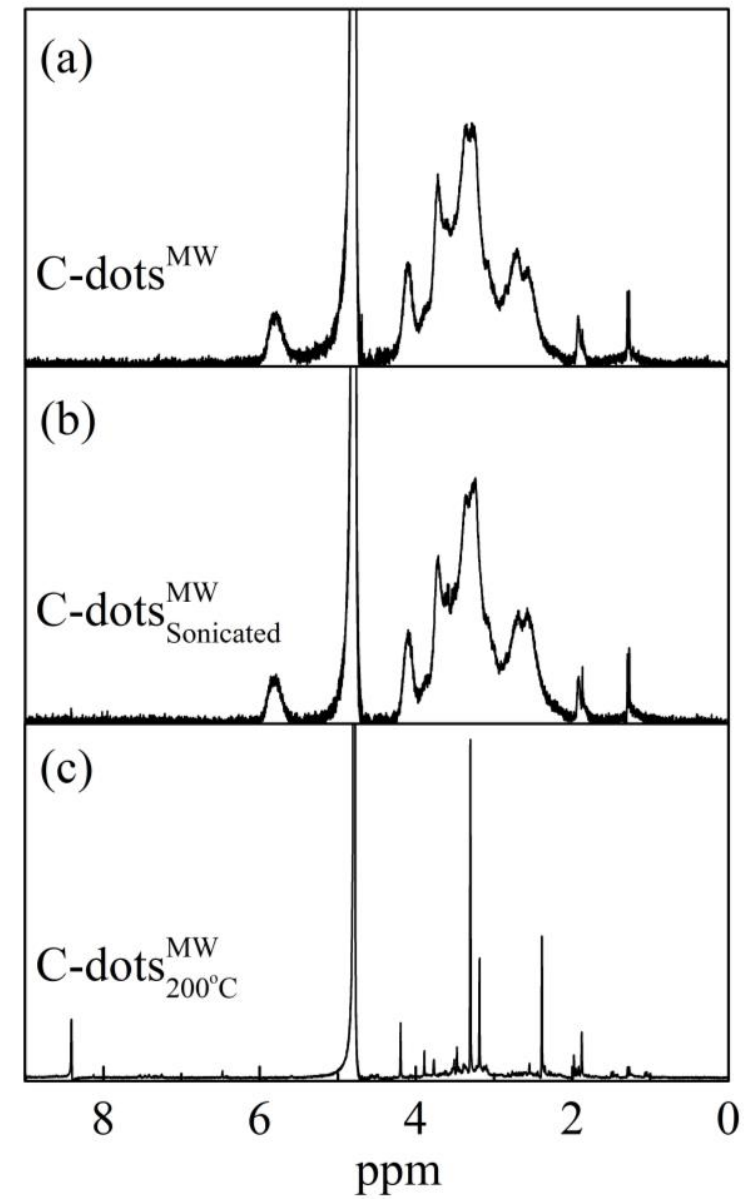

Figure S9: The ${ }^{1} \mathrm{H}$ NMR spectra of (a) the C-dots ${ }^{\mathrm{MW}}$ (b) the C-dots $\mathrm{Sonicated}^{\mathrm{MW}}$ and (c) C-dots $\mathrm{M}_{200^{\circ} \mathrm{C}}^{\mathrm{Mw}}$ in $\mathrm{D}_{2} \mathrm{O}$ solution. 


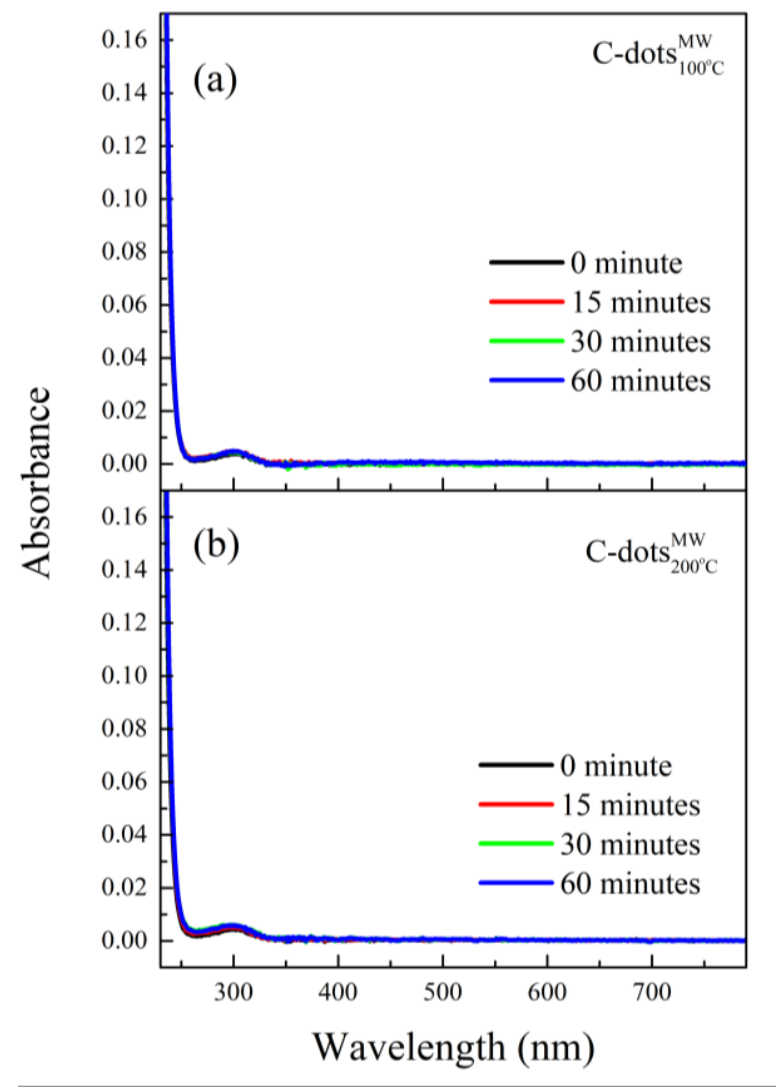

Figure S10: The absorption spectra of (a) the C- $\operatorname{dots}_{100^{\circ} \mathrm{C}}^{\mathrm{MW}}$ and (b) C-dots $\mathrm{S}_{200^{\circ} \mathrm{C}}^{\mathrm{MW}}$ mixed with AOT $(0.1 \%)+\mathrm{AgNO}_{3}$ and exposed to white light LED. The insets indicate the time-evolution of the absorbance at $430 \mathrm{~nm}$. 
Table S1: The relative area of each deconvoluted band of the XPS Spectra

\begin{tabular}{ccccccc}
\hline Deconvoluted band & $\alpha$ & $\beta$ & $\gamma$ & $\delta$ & $\varepsilon$ & $\zeta$ \\
\hline C-dots ${ }^{\mathrm{MW}}$ & 0.12 & 0.45 & 0.18 & 0.06 & 0.15 & 0.04 \\
C-dots $_{\text {sonicated }}^{\mathrm{MW}}$ & 0.44 & 0.38 & 0.05 & 0.14 & N.A. & N.A. \\
C-dots $_{100^{\circ} \mathrm{C}}^{\mathrm{MW}}$ & 0.18 & 0.50 & 0.04 & 0.15 & 0.11 & 0.02 \\
C-dots $_{200^{\circ} \mathrm{C}}^{\mathrm{MW}}$ & 0.21 & 0.29 & 0.18 & 0.28 & 0.03 & N.A.
\end{tabular}

